'the Washington consensus'. Ironically, at a time when Obama has overcome at least some of the huge odds against humane health reform in Washington, Richard's stay with UnitedHealth may have taken him more Rightwards than he has realised even by Washington standards!

In London, of course, there are enthusiastic neo-liberals (Tony Blair, for example: if you doubt me, just read his political autobiography, A Journey); and then there are fellow-travellers. The latter may or may not be enthusiastic, but they have accepted the terrain of neo-liberalism as the place for debate. I include the King's Fund and the Nuffield Trust in this pragmatists who have become just a bit too pragmatic.

And as Keynes knew, 'practical men' were often slaves to a defunct economist... 'pragmatists' in London often fail to see the opportunity cost of both market reform and endless tinkering with market models, of which Lansley's 'La La Land' is merely the most absurd yet.

And Richard, yes, power and responsibility should go together, for GPs as well as for all of us. My point was exactly that: if you don't maintain the balance between the two, you're in trouble. The government's dishonesty - selling '100\% the latter' as ' $100 \%$ the former' - is a sure way to disillusionment. Some GPs are often too trusting - at first - of reforms that promise to put them in the driving seat yet end up scorching their backsides in the hot seat.

And it's not just this government: Alan Milburn did the same in 2001, in New Labour's heyday. It's called the London consensus, you know!

\section{Calum Paton,}

School of Public Policy and Professional Practice, Darwin Building, Keele University, Keele, ST8 7LA.

E-mail: c.patonahpm.keele.ac.uk

\section{Calling time on the 10-minute consultation}

I read with interest the recent $B J G P$ editorial on 'Calling time on the 10-minute consultation.'. As a recently qualified GP working in one of the most deprived and ethnically diverse areas of the UK the concept of a one size fits all 10-minute consultation seems woefully outdated. As an individual practitioner I of course vary the length of my consultations based upon a multitude of patient factors, but there is always the underlying time pressure of a full surgery of patients waiting to be seen and of course the ubiquitous QOF targets. There is an undoubted effect of this time pressure on the way I practice, utilising time and followup appointments for complex cases. However, I wonder whether this time limitation could potentially impact on the ability of primary care practitioner's to make complex diagnoses early, a potential 'achilles heel' of general practice, ${ }^{2}$ thus adding to diagnostic delay and error, the biggest cause of medicolegal claims against GPs. ${ }^{3}$ Recent research has shown that health systems with a gatekeeper function have lower cancer 1-year survival. ${ }^{4}$ Around $23 \%$ of patients consult three or more times with a GP before suspected cancer referral, with increased repeat consultations in those from ethnic minorities and for certain cancers before referral. ${ }^{5} \mathrm{~A}$ Cochrane review into the effects of changing the length of primary care consultations found a lack of evidence, with only five UK trials meeting the inclusion criteria, with most having methodological weaknesses. ${ }^{6}$ They make the case for further research in this area, as without evidence the 10-minute consultation may still be the norm in 20 years time.

Thomas Round,

Primary Care Clinical Academic Fellow, Kings College London, Primary Care and Public Health, Capital House, 42 Weston Street, London, SE1 3QD.

E-mail: thomas.roundakcl.ac.uk

\section{REFERENCES}

1. Silverman J, Kinnersley P. Calling time on the 10minute consultation. Br J Gen Pract 2012. 62(596): 118-119.

2. Jones R. Diagnosis - still the achilles heel of general practice? John Fry Lecture. London: Royal Society of Medicine, 2011. http://www.rsmvideos.com/videoPlayer/?vid=209 \&class=videoThumbOdd (accessed 12 Apr 2012).

3. Kostopoulou O, Oudhoff J, Nath R, et al. Predictors of diagnostic accuracy and safe management in difficult diagnostic problems in family medicine. Med Decis Making 2008; $\mathbf{2 8 ( 5 ) : ~}$ 668-680.

4. Vedsted $\mathrm{P}$, Olesen F. Are the serious problems in cancer survival partly rooted in gatekeeper principles? An ecologic study. Br J Gen Pract 2011; DOI: 10.3399/bjgp11X588484

5. Lyratzopoulos G, Neal RD, Barbiere JM, et al. Variation in number of general practitioner consultations before hospital referral for cancer: findings from the 2010 National Cancer Patient Experience Survey in England. Lancet Oncol 2012; 13(4): 353-365.

6. Wilson AD, Childs S. Effects of interventions aimed at changing the length of primary care physicians' consultation. Cochrane Database Syst Rev 2006; (1): CD003540.

DOI: 10.3399/bjgp12X641366

In their editorial, Silverman and Kinnersley present a strong case for moving on from the 10-minute consultation. ${ }^{1}$ In 2011 an electronic 'consultation length' survey of all UK GP trainees (ST1-ST4) was undertaken by the RCGP Associates in Training committee. One of the key questions within the electronic survey was, what consultation length does your trainer offer for routine booked appointments?

A total of 1492 trainees completed the survey $1 \sim 15.8 \%$ out of $\sim 9451$ trainees contacted) providing proxy evidence of current consultation lengths offered by their GP trainers. The results of the survey are presented in Table 1.

When asked what would be the ideal consultation length be for routine booked appointments?' only $12.5 \%$ of trainees thought that 10 minutes was adequate. In contrast $55.9 \%$ believed that 15 minutes was needed. Reasons for trainees selecting 15 minutes included: "time for preventative care', 'thorough exploration of presenting problems', and 'greater patient satisfaction'.

This survey suggests that even in those practices that meet the quality standards for GP training, 15 minutes is still far from the norm. Yet, at the same time, it would appear that the next generation of GPs would agree with Silverman and Kinnersley that we should indeed call time on the 10-minute consultation.

\section{Table 1. GP trainer consultation length for routine booked appointments and trainee preference}

\begin{tabular}{lcc}
\multirow{2}{*}{$\begin{array}{l}\text { Consultation } \\
\text { length, minutes }\end{array}$} & Trainers & $\begin{array}{c}\text { Trainee } \\
\text { preference }\end{array}$ \\
\cline { 2 - 3 }$<5$ & $4(0.3)$ & 0 \\
\hline $5-9$ & $32(2.4)$ & $4(0.3)$ \\
\hline 10 & $1236(82.8)$ & $187(12.5)$ \\
\hline $11-14$ & $68(4.6)$ & $404(27.1)$ \\
\hline 15 & $102(6.8)$ & $834(55.9)$ \\
\hline 15 & $22(1.5)$ & $63(4.2)$ \\
\hline No set time & $28(1.9)$ & 0 \\
\hline
\end{tabular}


We are encouraged that trainees largely recognise that longer consultations are needed in general practice. This will undoubtedly need reorganisation within practices, but we have been able to offer 15minute appointments as standard for 8 years in our practice with huge benefits for ourselves, and we are confident, for patients' too. ${ }^{2}$

There is now substantial continued evidence that longer consultations can improve quality of care. ${ }^{3}$ With evidence and the opinions of younger GPs coming together we believe the RCGP and other NHS policy makers should unequivocally advocate 15-minute consultations.

Greg Irving,

Past Chair AiT Committee, RCGP, London. E-mail: greg.irvingaliv.ac.uk

John Holden,

GP, Garswood Surgery, Billinge Road, Garswood, Wigan.

\section{REFERENCES}

1. Silverman J, Kinnersley P. Calling time on the 10minute consultation. Br J Gen Pract 2012; 62(596): 118-119.

2. Holden J, Brown G. The introduction of repeat dispensing for 600 patients in one general practice. Int J Pharm Pract 2009; 17(4): 249-251.

3. Howie J, Maxwell M, Walker J, et al. Quality of general practice consultations: cross sectional survey. BMJ 1999; 319(7212): 738-743.

\section{The training capacity of general practice revisited: advanced training practices}

Dr Watton's inspirational project in advanced training practice capacity faces an uncertain future and he raises important questions on the development of community-based educational funding. ${ }^{1}$

The Project Surgery is a similar size practice, training 2nd and 5th year medical students, up to 3 VTS learners and some COPD work, with one partner also working as VTS programme director. We run this on mainstream funding only and also face a $20 \%$ cut in our core personal medical services budget. The future is unclear but such issues focus one's mind onto priorities.

With the advent of Local Educational Networks commissioning education and the unification of undergraduate, postgraduate medical and dental, and nursing training budgets into one income stream we have an opportunity to press for funding to flow into primary care as community-based education increases. The challenge will be to stand up to large block funded institutions and traditions of menu driven course based training, to develop what is core community training.

Our educational leaders will only navigate this murky swamp if they develop a vision of what the future could be. The Whitehouse Surgery stands as a beacon of possibilities to draw from. Colleagues who are core to our teams and unable to be trained outside primary care are doctors, nurses, and administrators, and so multidisciplinary training for these roles at all levels, in educationally integrated practice training teams, must be our first priority.

We must establish what will be core activity for the future of primary care and secure its mainstream funding if we are to realise the prize of widespread, advanced, and multidisciplinary training.

Petre Jones,

The Project Surgery, 10 Lettsom Walk,

Plaistow, London, E13 OLN.

E-mail: Petre.Jonesanhs.net

\section{REFERENCE}

1. Watton R. The training capacity of general practice revisited: advanced training practices. $\mathrm{Br}$ J Gen Pract 2012; 62(596): 135-154.

DOI: 10.3399/bjgp12X641384

\section{Situating general practice training in the general practice context}

Goldie and Morrison ${ }^{1}$ are right to emphasise the importance of the general practice context for postgraduate general practice training. In 1919 Sir James Mackenzie stated the teacher of practical matters must be one who experiences what he teaches. We all recognise that the best teacher for one who wants to be a shoemaker is the man who is in the habit of making shoes. Unfortunately, this common-sense idea is rarely applied to medical education'?

In 1952, the same year that our college was founded, the first integrated general practice training scheme pilot was set up in Inverness. Senior house officer level trainees had a 2-year contract to train concurrently in hospital and general practice. They were based for that whole period in one general practice. They started full-time in the practice for a few weeks and then spent 2-4 half-days every week in the same practice. The rest of the time was spent as a supernumerary experiencing different hospital departments and clinics according to their educational needs. They reported valuing the range and flexibility of the scheme. ${ }^{3}$

The compulsory postgraduate training for general practice that started in 1982 , requiring at least 2 years post full GMC registration in hospital and 1 year in general practice, seems in retrospect, almost a regression from the Inverness scheme of 30 years earlier.

Goldie and Morrison make important and relevant contextual observations about reflective practice, being part of a community of practice, and progressing through the Dreyfus model of skill acquisition. Current trends moving the delivery of care formerly given in hospital, to the community, and the super-specialisation of hospital departments, make this an opportune time to remove GP training from hospital, where what can be learned becomes less relevant to the future GP.

If the proposed 4-year trajectory of training for general practice that is currently mooted, becomes accepted, then there will be a real opportunity for trainees to spend, at the very least, 2 years training within general practice, in the community of practice in which their futures will be spent.

Paul Main,

Deputy Director, School of Primary Care, Severn Deanery.

E-mail: paul.maindsouthwest.nhs.uk

\section{REFERENCES}

1. Goldie J, Morrison J. Situating general practice training in the general practice context. $\mathrm{Br} J \mathrm{Gen}$ Pract 2012; 62(597): 217-218.

2. Mackenzie J. The future of medicine. London: Henry Frowde, Hodder \& Stoughton, 1919.

3. Horder JP, Swift G. The history of vocational training for general practice. J R Coll Gen Pract 1979; 29(198): 24-32.

DOI: 10.3399/bjgp12X641393 